\title{
Globalizing space and Earth science-the International Heliophysical Year Education and Outreach Programme
}

\author{
M. Cristina Rabello-Soares ${ }^{1}$, Cherilynn Morrow ${ }^{2}$, Barbara \\ Thompson $^{3}$ and David Webb ${ }^{4}$
}

${ }^{1}$ HEPL Solar Physics, Stanford University, 445 Via Palou, Stanford, CA 94305-4085, USA, csoares@sun.stanford.edu

${ }^{2}$ Space Science Institute, 4750 Walnut Street, Suite 205, Boulder, Colorado 80301, USA, morrow@SpaceScience.org

${ }^{3}$ Laboratory for Solar \& Space Physics, NASA Goddard Space Flight Center, Solar Physics Branch, Greenbelt, MD 20771, USA, Barbara.J.Thompson@nasa.gov

${ }^{4}$ ISR, Boston College, 140 Commonwealth Ave., Chestnut Hill, MA 02467 USA, david.webb@hanscom.af.mil

\begin{abstract}
The International Heliophysical Year (IHY) in 2007 \& 2008 will celebrate the 50th anniversary of the International Geophysical Year (IGY) and, following its tradition of international research collaboration, will focus on the cross-disciplinary studies of universal processes in the heliosphere.

The main goal of the IHY Education and Outreach Programme is to create more global access to exemplary resources in space and Earth science education and public outreach. By taking advantage of the IHY organization with representatives in every nation and in the partnership with the United Nations Basic Space Science Initiative (UNBSSI), we aim to promote new international partnerships. Our goal is to assist in increasing the visibility and accessibility of exemplary programmes and in the identification of formal or informal educational products that would be beneficial to improve space and Earth science knowledge in a given country; leaving a legacy of enhanced global access to resources and of world-wide connectivity between those engaged in education and public outreach efforts that are related to IHY science.

Here we describe how to participate in the IHY Education and Outreach Programme and the benefits in doing so. Emphasis will be given to the role played by developing countries; not only in selecting useful resources and helping in their translation and adaptation, but also in providing different approaches and techniques in teaching.
\end{abstract}

Keywords. education, Sun, solar-terrestrial relations, Earth, solar system, planets and satellites

\section{Introduction}

In 1957 a programme of international research, inspired by the International Polar Years of 1882 and 1932, was organized as the International Geophysical Year (IGY) to study global phenomena of the Earth and geospace in an unprecedented effort. The International Heliophysical Year (IHY) will celebrate the 50th anniversary of the International Geophysical Year (IGY) and, following its tradition of international research collaboration, will focus on the cross-disciplinary studies of universal processes in the heliosphere (Davila et al. 2004).

Nowadays, we routinely monitor the Sun, the interplanetary medium and the Earth's atmosphere. IHY represents a logical next-step from IGY, extending the studies into the heliosphere and thus including the drivers of geophysical change. The term 
"heliophysical" is an extension of the term "geophysical", where the Earth, Sun \& Solar System are studied as a whole domain.

\section{IHY overview}

International leaders have been identified throughout the world for this event and planning teams are already active in every region. Figure 1 illustrates the IHY organizational structure where the Steering Committee, Advisory Committee and Secretariat are charged with the guidance, execution and coordination of the international activities, respectively (see UNOOSA report 2006 for more information).

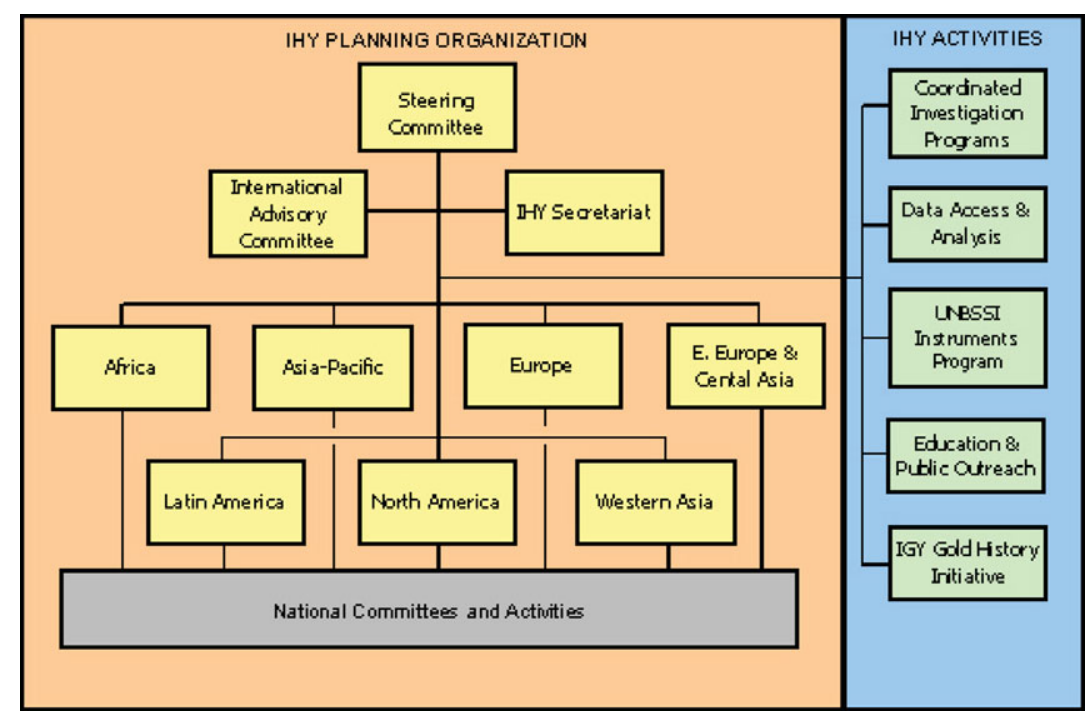

Figure 1. IHY organizational structure.

The IHY has three primary objectives:

- Advancing our understanding of the physical processes that govern the Sun, Earth and heliosphere;

- Continuing the tradition of international research and advancing the legacy on the 50th anniversary of the International Geophysical Year;

- Demonstrating the beauty, relevance and significance of space and Earth science to the world.

To achieve these goals, IHY is divided in four main components, called programmatic thrusts: Science activities, IHY/UNBSSI Observatory Development, Education and Public Outreach, and "IGY Gold" History Initiative.

IHY's scientific activities will be organized via Coordinated Investigation Programmes (CIPs) allowing cross-disciplinary studies and driving towards a more complete understanding of the universal processes that govern the Sun, Earth, planets and heliosphere (Harrison et al. 2005). It will involve scientists from a variety of disciplines: solar physics; planetary magnetospheres; heliosphere and cosmic rays; planetary ionospheres, thermospheres and mesospheres; climate studies; and heliobiology (i.e., study of the space environment's influence on and interaction with biological systems and processes).

The IHY/UNBSSI Observatory Development is in collaboration with the United Nations Basic Space Science Initiative (UNBSSI) of the UN Office for Outer Space Affairs (UNOOSA) and is dedicated to stimulating research on Earth and space science, 
specially in developing nations, through the deployment of small-instrument arrays around the world (see Gopalswamy et al. 2006).

The "IGY Gold" History Initiative aims to preserve the history and legacy of IGY by identifying and recognizing planners of and participants in the IGY, preserving and making available items of historical significance from the IGY, and organizing commemorative activities and events.

The Education and Public Outreach component, which is the subject of this paper, is dedicated to bringing heliophysics education to all the people of the world.

\section{IHY Education and Public Outreach Programme}

"Demonstrate the beauty, relevance and significance of space and Earth science to the world" - this IHY basic objective is the focus of the Education and Public Outreach (EPO) Programme. IHY presents unique opportunities for expanding the education and awareness of space and Earth science. As a result, the education programme forms a cornerstone of IHY.

The programme aims to inspire the next generation of space and Earth scientists and explorers; and spread the knowledge of our solar system and the exciting process of scientific exploration to the people of the world. Encouraging young people to pursue careers in science and technology helps secure and, in the case of developing nations, build up human resources, which will improve the technological base and enhance the prospect for further development.

As hundreds of observatories and institutions are preparing for the scientific activities of IHY, the associated educational programmes are being linked into a worldwide network of schools, institutes, programmes and activities. In addition, the IHY programme was developed in conjunction with the United Nations. As a result, the IHY EPO programme is well situated to promote new international partnerships, bringing heliophysics education to all the people of the world. Our goal is to assist in increasing the visibility and accessibility of exemplary programmes and in the identification of formal or informal educational products beneficial to a given country. The programme aims to provide greater international exposure for existing programmes but also and foremost to make them accessible to regions where there are few EPO resources available. Furthermore, we aspire to leave a legacy of enhanced global access to resources and world-wide connectivity between those engaged in education and public outreach efforts in space and Earth science.

The organizational structure of the IHY EPO programme closely mirrors the overall organization of the IHY programme: a central coordinator, an advisory committee and educators serving as national coordinators for EPO (Table 1). The central coordinator is part of the IHY secretariat and serves as a contact point and facilitator for the IHY team members and their EPO activities. The EPO national coordinator is appointed by the IHY national coordinator and acts as the liaison between those working on education and public outreach in his/her country and the IHY secretariat, as well as to the coordinators of the other nations. The national coordinator for EPO is responsible for promoting local activities and inviting exemplary EPO programmes in their country to be a participating programme in the IHY.

To foster the partnerships and facilitate the access to exemplary programmes our website (http://ihy2007.org/outreach/outreach.shtml) lists the participating programmes with a links to their resources, which are available to all. They are asked to fill out a form where they are divided into the following categories: formal education (curriculum development, professional development, schools, colleges, universities); informal 
Table 1. IHY national coordinators for EPO.

\begin{tabular}{ccl}
\hline Country & Coordinator & Institute \\
\hline BRAZIL & Adriana V.R. da Silva & MacKenzie University, Sao Paulo \\
BULGARIA & Penka Stoeva & Bulgarian Academy of Sciences \\
CZECH REPUBLIC & Rostislav Halas & Realne Gymnasium, Prostejov \\
FINLAND & Heikki Nevanlinna & Finnish Meteorological Inst., Helsinki \\
GERMANY & Frank Jansen & University of Greifswald, Greifswald \\
JAPAN & Shinichi Watari & Nat. Inst. of Info. \& Com. Tech. \\
JORDAN & Hanna Sabat & Al al-Bayt University, Mafraq \\
MALAYSIA & Azreena Ahmad & National Space Agency, Putrajaya \\
MEXICO & Guadalupe Cordero & Instituto de Geofisica, Coyoacan \\
NIGERIA & Ayodele Faiyetole & English Obafemi Awolowo Univ.,Ile-Ife \\
NORWAY & Arve Aksnes & University of Bergen, Bergen \\
PERU & Maria-Luisa A. Hurtado & Univ. Nac. de San Marcos, Lima \\
SLOVAKIA & Karel Kudela & Slovak Academy of Sciences Kosice \\
SOUTH AFRICA & Lee-Anne McKinnell & Rhodes University, Grahamstown \\
SPAIN & Javier Rodriguez-Pacheco & Universidad de Alcala, Madrid \\
SWEDEN & Henrik Lundstedt & Swedish Inst. of Space Phys., Lund \\
UNITED KINGDOM & Lucie Green & University College London \\
UNITED STATES & Cherilynn Morrow & Space Science Institute, Boulder, CO \\
YEMEN & Nada Alhaddad & University of Sana'a \\
\hline International Coordinator & M.C. Rabello-Soares & Stanford University, California, USA \\
\hline
\end{tabular}

education (museums, science centers, planetariums); mass media (news, video, journalism); clubs and community groups (e. g. youth groups, scouts, amateur astronomy clubs); evaluation and research; scientist in education (e.g. scientist who gives public talks); and last but not least translation. A searchable database where the participating programme data can be updated at any time by its leader will be available soon.

A good example of a participating programme is the Space Weather Monitor Project which is also part of the IHY/UNBSSI Observatory Development (see Scherrer et al. 2006). It will bring hands-on science to pre-college students in developing countries. It consists of inexpensive monitors used to track solar- and lightning-induced changes to the Earth's ionosphere. The project also provides classroom support materials in the six official languages of the United Nations.

Determining the need for multi-lingual adaptations of educational resources and facilitating their translation is an important aspect to accomplish our goal of globalizing heliophysics outreach. Participating programmes able to assist with the translation and adaptation are of great importance. Institutions and individuals are encouraged to help in this effort. Scientists and educators of developing countries play an important role not only in the selection of useful resources, but also in helping with the translation and dissemination of the EPO resources that they believe will improve science literacy in their countries. The available multilingual resources are accessible to all at our website. At the moment, among the languages that we have support to translate from and to English are: Arabic, Armenian, Azerbaijani, Chinese, Czech, French, Gaelic, German, Greek, Japanese, Polish, Portuguese, Romanian, Russian and Spanish. We hope to expand this further.

As IHY establishes a greater presence for research in space and Earth science in developing countries through the IHY/UNBSSI Observatory Development, it will provide opportunities for undergrad and grad students to participate actively in an international cutting-edge research project. In this way, IHY will foster the development of graduate 
and undergraduate programmes which, in turn, will encourage young people to become interested in the exciting field of heliophysics. Stronger research programmes mean stronger universities. To reinforce education at college level, the IHY has created the IHY Schools Programme to develop a series of schools in 2007 with the purpose of educating students in heliophysics.

\subsection{IHY Schools Programme}

The IHY Schools Programme is organized and operated by the IHY Schools Committee (ISC). The ISC consists of the following members: David Webb (Coordinator), Ilia Roussev, Nat Gopalswamy, M. Cristina Rabello-Soares (EPO Coordinator), Don Hassler, Cristina Mandrini, and Barbara Thompson. The ISC will initially invite and support students that are associated with two IHY thrusts: the Coordinated Investigation Programmes (CIPs) and the IHY/UNBSSI Observatory Development Programme.

At least four IHY schools are being planned in 2007. One will be in Boulder (Colorado, USA) to serve North America and is led by Don Hassler and David Webb. The second will be held at the ICTP in Trieste, Italy for the European/African region and is led by Nat Gopalswamy. The third will be in Latin America and is led by Cristina Mandrini. The last will be in the Asia-Pacific region and the leader will be determined soon. Additional schools under the IHY umbrella are being considered in individual countries.

The overall scope of the schools will be heliophysics, including its universal processes, Sun-Earth interactions as well as those at other planets, and the outer heliosphere. The schools will include seminars and hands-on data analysis sessions with databases acquired particularly through the CIPs and IHY/UNBSSI programmes, and collaborative efforts with other affiliated groups such as CAWSES, the European COST 724, NASA, NSF, AFOSR and the IAU. Each school will be encouraged to select local lecturers and students from their regions so as to reduce costs. The help of the appropriate national and regional IHY coordinators will be sought.

The ISC is developing a general curriculum that will be used as a model for all four schools. The curriculum will include lectures in the following universal physical processes in heliospace: 1) evolution and generation of magnetic structures and transients, 2) energy transfer and coupling processes, 3) flows and circulations, 4) boundaries and interfaces, and 5) synoptic studies of the 3-D coupled solar-planetary-heliospheric system.

\section{Conclusions}

The International Heliophysical Year in 2007-2008 presents a unique opportunity for expanding education on space and Earth science and to demonstrate the beauty, relevance and significance of space and Earth science to the world.

The developing countries have an important role in IHY not only in selecting useful resources, helping in the translation/adaptation and disseminating the resources to the teachers and general public, but also in providing different and innovative approaches and techniques in teaching.

\section{Acknowledgement}

MCRS is supported by NASA grant NNX06AD10G.

\section{References}

Davila, J.M., Poland, A.I. \& Harrison, R.A. 2004, Adv. Sp. Res. 34, 2453 
Gopalswamy, N., Davila, J.M., Thompson, B. \& Haubold, H.J. 2006, in: J. Hearnshaw \& P. Martinez (eds.), these proceedings

Harrison, R.A, Breen, A., Bromage, B. \& Davila, J.M. 2005, Astronomy 83 Geophysics 46, June 2005

Scherrer, D., Rabello-Soares, M.C. \& Morrow, C. 2006, in: J. Hearnshaw \& P. Martinez (eds.), these proceedings

United Nations Office for Outer Space Affairs (UNOOSA) 2006, Putting the "I" in the IHY: Comprehensive overview on the worldwide organization of the International Heliophysical Year 2007 (United Nations, Austria), V.05-89935, February 2006

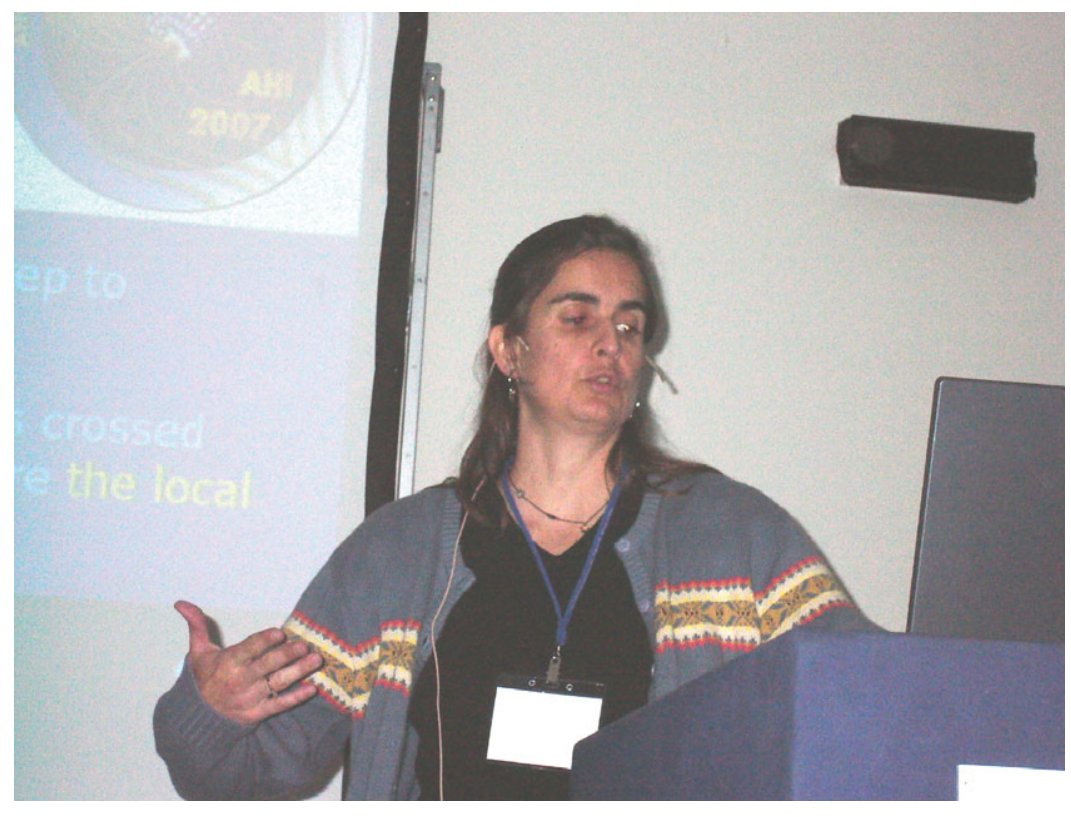

Cristina Rabello-Soares 